\title{
Author Correction: Age-associated mitochondrial DNA mutations cause metabolic remodeling that contributes to accelerated intestinal tumorigenesis
}

Anna L. M. Smith, Julia C. Whitehall, Carla Bradshaw, David Gay, Fiona Robertson, Alasdair P. Blain, Gavin Hudson, Angela Pyle, David Houghton, Matthew Hunt, James N. Sampson, Craig Stamp, Grace Mallett, Shoba Amarnath (D), Jack Leslie (D), Fiona Oakley, Laura Wilson, Angela Baker, Oliver M. Russell, Riem Johnson, Claire A. Richardson, Bhavana Gupta, lain McCallum, Stuart A. C. McDonald, Seamus Kelly, John C. Mathers, Rakesh Heer, Robert W. Taylor, Neil D. Perkins, Doug M. Turnbull, Owen J. Sansom (D) and Laura C. Greaves (D)

Correction to: Nature Cancer https://doi.org/10.1038/s43018-020-00112-5, published online 21 September 2020.

In the version of this article initially published, the Acknowledgements section lacked recognition of the Newcastle University Bioimaging Unit. The correct beginning of that section is as follows: "We thank T. Prolla (University of Wisconsin, Washington, USA) for donating the PolgA $A^{+/ m u t}$ mice, and C. Alston for assistance in the analysis of mtDNA mutations. We thank staff in the Newcastle University Comparative Biology Centre for the animal husbandry, and the Newcastle University Bioimaging Unit for support and assistance with fluorescent imaging." The error has been corrected in the HTML and PDF versions of the article.

Published online: 30 November 2020

https://doi.org/10.1038/s43018-020-00156-7

() The Author(s), under exclusive licence to Springer Nature America, Inc. 2020 